\title{
Legal protection of the mentally ill: Report of Lesotho Conference
}

\author{
by Graham Ritchie
}

\begin{abstract}
Graham Ritchie, Director of the International Professional Training and Research Unit (IPTRU) at the Institute of Advanced Legal Studies, spoke at a conference on the Legal Protection of the Mentally Ill, which took place at Maseru, Lesotho, on 30 July -1 August. His report on the conference (below) is followed by an account of his presentation.
\end{abstract}

\section{CONFERENCE REPORT}

$\mathrm{T}$ the Conference was opened by the Deputy Prime Minister and Minister of Justice, and the Minister for Health and Welfare. The main thrust of the presentations, and the discussion by the participants, was concerned with the need to raise awareness levels with regard to the rights and dignity of mentally ill and incapacitated persons, not only among professional disciplines, but also in the general public. Great weight was placed upon the importance of continuing relevant training for the professionals involved in the various aspects of the care and treatment of mental patients.

The issue of empowerment of the mental patient was a topic which developed significant debate, both as regards principles and good practice to be adopted and followed, and in respect of the practicalities of enabling this to take place in day-to-day practice. These themes were examined from all the aspects which could be raised by an authoritative assembly of some 60 senior professionals and academics, judges, Government Ministers and their officials.

A significant theme of the conference was the mental health needs of children, and local concerns were illustrated by discussions turning on the problems of 'street children'. A further area of local concern was the effect of the HIV/AIDS epidemic on mental health issues. Treatment of mental patients within the criminal justice system was another focus of attention, with particular emphasis on the question of detention within secure units of persons who are either not susceptible to treatment, or who are only temporarily seriously mentally ill. The lacunae in the Lesotho legislation were identified as meriting an early legislative cure. Indeed, it was generally acknowledged that the Lesotho statutes concerning mental health are very out of date, do not reflect present day psychiatric or lay thinking, and urgently in need of reform.
The role of the mental health professional in enhancing the rights of mental patients was considered in the light of the contrasting situations in Lesotho, South Africa and the UK. The need for improvements in practice was acknowledged, but changes in the legal framework were considered to be an essential component for underpinning such developments. The role of the criminal law in providing protection for the vulnerable mental patient, especially in connection with rape and sexual abuse, was a further matter which gave rise to lively debate on the need for, and the direction of, law reform in this area.

As set out in the speech given by the Minister of Justice, and firmly stated by the Minister for Health in out-ofconference discussion, the government of Lesotho is committed to addressing reform of the law on mental health as a matter of priority. Ministries, the Attorney General, the High Court judiciary and the Lesothon have made repeated requests for assistance with this representative of the World Health Organisation. The culminating act of the conference was to make a number of resolutions for consideration by government.

\section{PROTECTION OF THE MENTALLY ILL: A HISTORICAL OVERVIEW OF THE LAW, LESSONS LEARNED AND THE LEGISLATIVE WAY FORWARD}

The history of modern psychiatry is accepted to have a beginning with the unshackling of manacled mental patients in revolutionary Paris in 1792. Pinel, the man responsible for transforming French society's perception of the mad as people who are alien, and of diminished humanity, into people who are just sick, and often curable men and women, caused a change in perception of the mentally ill amongst the medical profession. The 
perception of the mentally ill by society at large however, remains negative.

To the ordinary person, the mentally ill are strange and frightening. The mentally ill are beings not as we are and our interaction with them is artificial. We are inclined to see them as beings with less human dignity and we interact with them as though they are not quite members of the human family. Unlike other ill adults the mentally ill adult may sometimes receive treatment and care either against his will, or with his uncomprehending acquiescence. The treatment and care of the mentally ill is therefore often treatment without consent.

Consent of a patient has always been a necessary precursor to treatment. The case of Slater $\mathrm{v}$ Baker and Stapleton (1767) 2 Wils KB 359, is typical of this point of view, where the judge said that the need for a patient's consent was 'the custom and usage of surgeons'. The fact that mental patients do not always have the capacity to give consent to treatment in many instances means that legalism and 'medicalism' are inevitable bedfellows in the treatment and care of the mentally ill.

The profession of psychiatry has therefore developed hand in hand with the development of administrative and legal controls of the power of psychiatrists. Unlike the perception of mental patients as being strange and not fully human beings, mental patients are fully human and often intelligent, articulate, and sensitive. Every human being alive could have the misfortune of a neurological or reactive mental illness, as every person runs the risk of falling victim to any physical condition. John Percival, a mental patient, gave an account of his treatment without consent in the 1830s. He later acknowledged that he needed treatment but the administration of this treatment reveals the attitudes to the mentally ill that always seem to apply.

John Percival wrote in his A Mad Peoples History of Madness (University of Pittsburgh Press, Pittsburgh, PA, 1982):

'Men acted as though my body, soul and spirit were fairly given up to their control, to work their mischief and folly upon. My silence, I suppose, gave consent. I mean that I was never told such and such things we are going to do; we think it advisable to administer such and such medicine in this or that manner. I was never asked; do you want anything? Have you any objection to this or that? I was fastened down in a bed; a meagre diet was ordered for me; this and that medication forced down my throat, or in the contrary direction; my will, my wishes, my repugnance's, my habits, my delicacy, my inclinations, my necessities, were not consulted, I may say thought of. I did not find the respect paid usually even to a child.'

The 19th Century English poet John Clare revealed his pain of mental illness in his poem I Am:

'I am: yet what I am none cares or know,

My friends forsake me like a memory lost,

I am the self-consumer of my woes,
They rise and vanish in oblivion's host, Like shades in love and death's oblivion lost, And yet I am, and live with shadows tost. Into the nothingness of scorn and noise, Into the living sea of waking dreams,

Where there is neither sense of life nor joys,

But the vast shipwreck of my life's esteems

And even the dearest - that I love the best

Are strange - nay, rather stranger than the rest.'

In the United Kingdom the use of physical restraint, such as shackling patients to the wall on a permanent basis and keeping them naked and barely fed, eventually ceased to be acceptable to society at large. Legal intervention in the treatment and care of patients became formalised with the Lunatic Asylums Act of 1845. This act conferred control of the treatment of unsoundness of mind on the emergent psychiatric profession, subject to the supervision of the national Lunacy Commission. Psychiatrists formed the Association of Medical Officers of Hospitals for the Insane in 184, which became the Medic-Psychological Association in 1865 . The regulatory strategy of the Lunacy Commission was to exercise surveillance of the use of coercive interventions, rather than to seek their total elimination.

Even though coercive restraint and heavy sedation were not viewed as recognised treatments for insanity, they were recognised as treatments for the control of disturbed behaviour. The various commissions- including the present United Kingdom Mental Health Act Commission - which have regulated the mental health sector and the supervision of the courts through the use of judicial review, have played an important role in shaping the perception of what is acceptable.

The entire debate revolves around the issue of confinement and treatment without consent. What can and cannot be deemed to be consent, and whether there needs to be consent to care as well as consent to treatment, is what is called 'care in fact treatment'. This is an important point because under the Mental Health Act 1983 (England and Wales), there are statutory safeguards against inappropriate or oppressive uses of treatment without consent, but care is seen as a non-medical issue that does not need statutory safeguards.

The most recent source of inspiration for consideration of these issues, which have been with us since the early 19th Century, and which will always be with us in the future, are the various conventions on human rights. For example the European Convention on Human Rights was used as authority to urge the introduction of greater procedural safeguards and tighter regulation of psychiatry. These procedural safeguards were incorporated in the UK Mental Health Act 1983. The aim was to introduce at the time a new legalism but to try to avoid a cumbersome and technical legal formalism. 
Article 5 of the European Convention on Human Rights requires that any decision to detain a person on grounds of unsoundness of mind to be free from arbitrariness (Van der Leer v The Netherlands (1990) 12 R 567). Three conditions must be satisfied before detention and the administering of compulsory treatment can take place:

(1) It must be reliably shown by competent medical authority, on the basis of objective expertise, that the patient is of unsound mind.

(2) The condition must warrant compulsory confinement.

(3) Continued confinement is dependent on the persistence of mental disorder (Winterwerp v The Netherlands (1979) 2 EHRR 387).

We are therefore at a stage where the solicitor and writer Anselm Eldergill can justly say:

'Promoting liberty, protecting individuals from the harm caused by those at liberty, and those not at liberty from abuse by those who are at liberty, alleviating suffering, and restoring to health those whose health has declined, are all legitimate objectives, in that they reflect values embraced by virtually all members of our society,' Eldergill, 1997: 45.

Such a situation is however under constant threat. The perception of people in general is that the mentally ill are strange, frightening, and dangerous. This is an atavistic response of the mentally well to the mentally unwell. It has existed throughout time and the consequences of this attitude have only been ameliorated by the developments described above. A minority of the mentally ill can of course be very dangerous and a statistically small number of murders and other crimes against the person are perpetrated by the mentally ill. The response of UK society to this danger is the UK Government White Paper 2000 on the reform of the Mental Health Act 1983. The thrust of the White Paper is to achieve the maximum protection of the public not only from those defined as mentally ill within the terms of the Mental Health Act 1983, but also those who maybe deviants, inadequate, mentally disabled, people with an untreatable personality disorder, and perhaps less controversially untreatable psychopaths.

In order to protect the public from these categories of dangerous people proposed legislation runs the risk of removing the legislative, common law, and practice safeguards and protection of the mentally ill which has been built up over two centuries. The UK Government is not unresponsive to the fears expressed by professionals about the proposed changes and the White Paper on the subject is now to be subject to a continuing discussion for a further period of time.

The acutely mentally ill who need to be confined and provided with treatment and care on a compulsory basis are a relatively small minority. During 1999 the average number of compulsorily detained patients in England and
Wales on any one day was approximately 13,000. On any one day in England and Wales in 1999 there were a further 22,000 patients in hospital as voluntary patients, or patients who did not have the capacity to form an attitude, or to express an attitude of objection to their stay in hospital. These patients are known as 'informal patients' because they have not been admitted to hospital under legal compulsion as 'formal patients.'

The case of $R \mathrm{v}$ Bournewood Mental Health Trust, ex parte $L$ (1998) 3 WLR 107-128 raised the following issue: What is the legal position if an informal patient is making no attempt to leave hospital but if they had tried to do so they would have been physically detained?

At the Court of Appeal stage of this case it was decided that in a practical effect an informal patient would be a compulsory patient. In which case then they should be made formal compulsory patients under the law, in order for them to benefit from the checks and balances and legal protections afforded formally detained patients. (That case is fully described in the 'The Bournewood fright,' G Ritchie, Amicus Curiae 14, February 1999).

The House of Lords overturned the Court of Appeal decision. The further case of $R \mathrm{v}$ Mental Health Act Commission ex parte Smith (1998) 43 BMLR 174, came to a parallel conclusion when considering whether 'care', (i.e. management, control, nursing, etc), was the same as 'treatment' for legal purposes. This was an important question because the Mental Health Act Commission could supervise elements of 'treatment' but the Commission did not think that it had the authority to supervise 'care'. In this case the patient died because of a failure of 'care'. The judge in this case said that the Commission could investigate 'care', because, as he said:

Any complaints arising out of the exercise of the power to detain, manage and control, and the duty to treat, are complaints in respect of which the Commission has jurisdiction. It seems to me that management, control and treatment all form part of the package of compulsion which is the essence of formal detention.' (paraphrase).

This means that anyone kept in hospital by legal process has the right for all aspects of the acts and omissions perpetrated on them in hospital to be scrutinised by the supervisory body the Mental Health Act Commission.

The 'Bournwood fright' case also illustrated the point that all the issues of legalism and medicalism being considered today have already been considered by our forefathers and that any thought of developing or amending legal and medical practice in this area should take place in the light of what has happened before.

Graham Ritchie, MA (Cantab), solicitor

Director of the International Professional Training and Research Unit (IPTRU) at the Institute of Advanced Legal Studies 